\title{
Oblique crushing performances of hybrid woven Kenaf fibre reinforced aluminium hollow cylinder
}

\author{
Al Emran Ismail, Mohd Norihan Ibrahim, Saifulnizan Jamian, Kamarul-Azhar Kamarudin, Muhammad Khairudin Awang, and \\ Mohd Khir Mohd Nor
}

Crashworthiness and Collision Research Group (COLORED), Mechanical Failure Prevention and Reliability (MPROVE), Faculty of Mechanical and Manufacturing Engineering, Unviersiti Tun Hussein Onn Malaysia, Batu Pahat, 86400 Johor, Malaysia

\begin{abstract}
This paper presents crushing performances of hybrid woven kenaf fibre reinforced aluminium tubes under axial and oblique compression. According to open literature, lack number of works conducted to study the crushing responses when kenaf fibre in the form of woven is used to reinforce aluminium tubes. There are important parameters are used such as fibre orientations and oblique compression angles. Kenaf fibre in the form of woven is firstly wetted with polyester resin before it is wrapped around the tubes. After composite hardened, the hybrid tubes are quasi-statically compressed and force-displacement curves are recorded. Energy absorption performances are then determined and discussed in term of different fibre orientations and oblique angles. It is found that $\left[ \pm 30^{\circ}\right]$ fibre orientations capable to produce higher force-displacement responses and hybrid tubes are produced lower force ratio indicating the role of natural fibre in increasing the capability of energy absorptions.
\end{abstract}

\section{Introduction}

Crashwothiness is an engineering field considering safety aspects of vehicle integrity during collisions and impact. It is not only concentrated on the safety of passengers or occupants inside the vehicles but it is also considered the safety of pedestrians. In general metallic structures for example steel is widely used to fabricate the vehicle components and recently aluminium alloy is also used since it is offered high ratio of strength to weight. In front of vehicles, most of designers placed cashboxes to ensure during collusion some of kinetic energy will be absorbed and therefore reducing injuries among occupants.

During collision, plastic deformation is the only mechanism contributed to absorb impact energy and tremendous number of publications can be found elsewhere [1-4]. Eyvazian et al. [1] investigated axial crushing behaviour of corrugated tubes made of aluminium tubes. They used five different geometries of corrugations and simple tube for comparisons. It is found the crushing behaviour is affected by the corrugated geometries since the introduction of design defect capable to control the collapse behaviour of the tubes. A mathematical aspect of corrugated tube under axial compression can be found in [2].

Huang et al. [3] investigated dynamic crushing characteristics of high strength steel cylinder with elliptical geometric discontinuities. Finite element analysis is used to study the influence of cut-out locations, cut-out shapes and symmetry of cut-out on the crushing performances. They found that cut-out capable to significantly affect the energy absorption capability. If the cut-out is positioned in the middle, the tube tend to experience a global buckling whereas it is placed at an upper or bottom ends progressive collapse can be obtained.

Galib and Liman [4] experimentally and numerically investigated circular aluminium tubes under static and dynamic loading. They have shown that the comparison of the mean force from different solutions gave good concordance between them. They added that this type of analysis is expected to be a useful approach in the design before actual experimentations can be conducted.

Some researchers used synthetic fibre reinforced composites and it is wrapped around the energy absorbing device. The purpose is to enhance the performances of crushing behaviour. For examples Kalhor et al. [5] wrapped steel square tube with glass/epoxy composites before it is quasi-statically crushed to investigate the responses of force versus displacement curves. Numerical modelling is also developed in order to obtain optimum crashworthiness aspects.

El-Hage et al [6] numerically characterized square aluminium-composite hybrid tubes under axial compression. Fibre orientations are varied with respect to the axis of tubes. It is found that hybrid tubes produced higher energy absorption than aluminium tube alone. Shin et al. [7] found similar behaviour where hybridizing the tube with synthetic fibre capable to improve the crushing performances.

Recently, due to environmental awareness among 
researchers and industrialists, natural fibres are given a bright opportunity to replace synthetic fibres. Some review papers on the potential of natural fibre can be found in [8-11]. Hybridizing metallic tubes with natural fibres are very difficult to find. There are several papers conducted to investigate the crushing responses can be found [12-19]. Most of these papers found that natural fibre capable to increase the capacity of energy absorption.

This paper present crushing performances of woven kenaf fibre mat wrapped around aluminium tubes. Different fibre orientations are used and it is quasistatically compressed in order to obtain the force versus displacement curves. During crushing processes, the samples are not only crushed axially but obliquely. Energy absorption capability is calculated and discussed in correlating with fibre orientations and oblique compression.

\section{Methodology}

An industrial grade aluminium hollow tube is used with thickness of $1 \mathrm{~mm}$ and $50 \mathrm{~mm}$ external diameter. The length of tube is $100 \mathrm{~mm}$ where it is long enough to prevent global buckling. As-received kenaf yarn (as in Figure 1(a)) is weaved into a plain woven mat before it is wrapped around the outer surface of aluminium tube. The weaving process is conducted using an in-house facility as in Figure 1(b) and 1(c). While Figure 1(d) revealed the completed woven kenaf mat.

Woven kenaf mat is firstly immersed into a resin bath where a proper care is given in ensuring resin penetrates into the fibres uniformly. The wet fibre mat is wrapped around the tube twice and each layer oriented according to the specific orientation as tabulated in Table 1.

Figure 2 shows the completed hybrid woven kenaf/aluminium hollow tube. This sample is positioned vertically between two flat rigid plates. The bottom plate is stationary while the upper one is moved downward. The sample is compressed quasi-statically with a speed of $1.5 \mathrm{~mm} / \mathrm{min}$ of cross-head displacement. The force versus displacement curves are recorded automatically where the area under the curves represent the capability of energy absorption, E and it can be represented as:

$$
E=\int_{0}^{L} P d s
$$

where $\mathrm{P}$ is a force, ds is a small element on the curve and $\mathrm{L}$ is the crushed length. Instead of energy absorption performance, other important parameter such as force ratio, $\psi$ is also determined as in Equation (2).

$$
\psi=\frac{P_{\text {mean }}}{P_{\text {peak }}}
$$

where $\mathrm{P}_{\text {mean }}$ is the average force during the crushing process and $\mathrm{P}_{\text {peak }}$ is the maximum or peak force just after the elastic deformation. Final crushed samples are also observed in order to study the effect of variations of fibre orientations on the crushing performances.

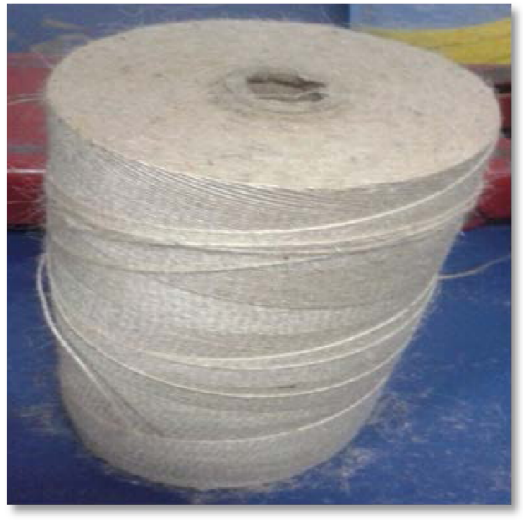

(a)

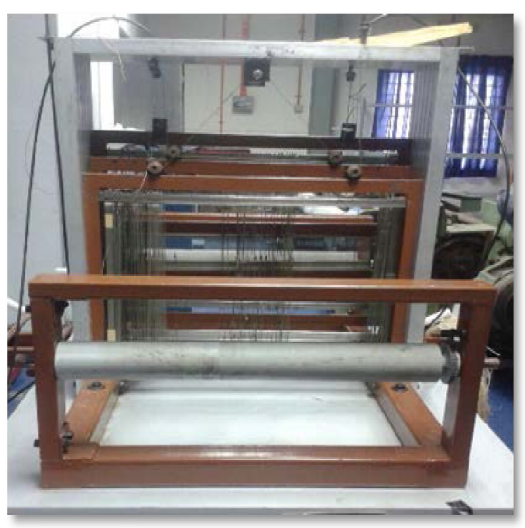

(b)

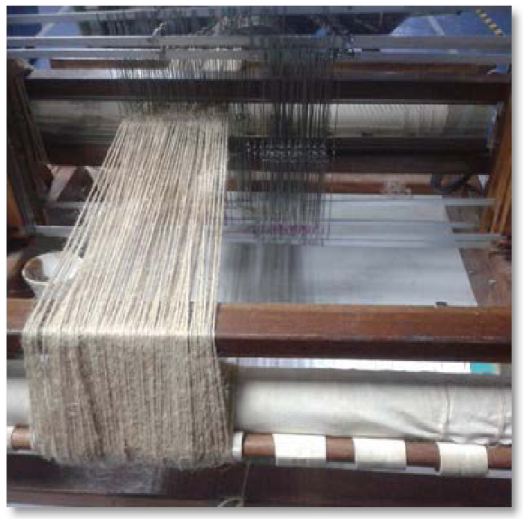

(c)

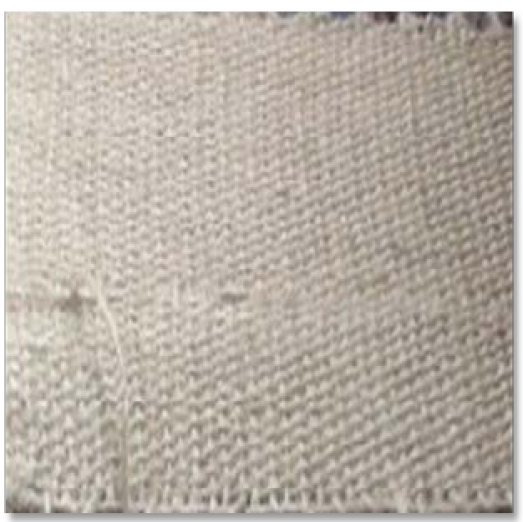

(d)

Figure 1. (a) As-received kenaf yarn, (b) Weaving machine, (c) Weaving process in progress and (d) Completed woven kenaf mat. 
Table 1. Sample parameters and compression conditions.

\begin{tabular}{|c|c|c|c|}
\hline No. & Orientations & Layers & Oblique Angles \\
\hline 1 & \multirow{4}{*}{ Empty tubes } & - & $0^{\circ}$ \\
\hline 2 & & - & $5^{\circ}$ \\
\hline 3 & & - & $10^{\circ}$ \\
\hline 4 & & - & $15^{\circ}$ \\
\hline 5 & \multirow{4}{*}[\pm0]{} & 2 & $0^{\circ}$ \\
\hline 6 & & 2 & $5^{\circ}$ \\
\hline 7 & & 2 & $10^{\circ}$ \\
\hline 8 & & 2 & $15^{\circ}$ \\
\hline 9 & \multirow{4}{*}[\pm15]{} & 2 & $0^{\circ}$ \\
\hline 10 & & 2 & $5^{\circ}$ \\
\hline 11 & & 2 & $10^{\circ}$ \\
\hline 12 & & 2 & $15^{\circ}$ \\
\hline 13 & \multirow{4}{*}[\pm30]{} & 2 & $0^{\circ}$ \\
\hline 14 & & 2 & $5^{\circ}$ \\
\hline 15 & & 2 & $10^{\circ}$ \\
\hline 16 & & 2 & $15^{\circ}$ \\
\hline 17 & \multirow{4}{*}[\pm45]{} & 2 & $0^{\circ}$ \\
\hline 18 & & 2 & $5^{\circ}$ \\
\hline 19 & & 2 & $10^{\circ}$ \\
\hline 20 & & 2 & $15^{\circ}$ \\
\hline
\end{tabular}

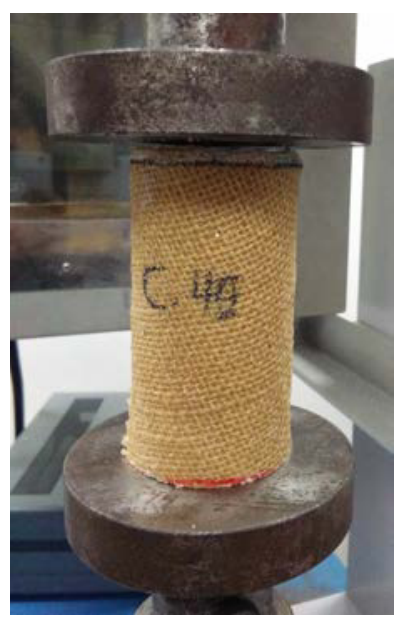

Figure 2. Hybrid woven kenaf/aluminium hollow tube.

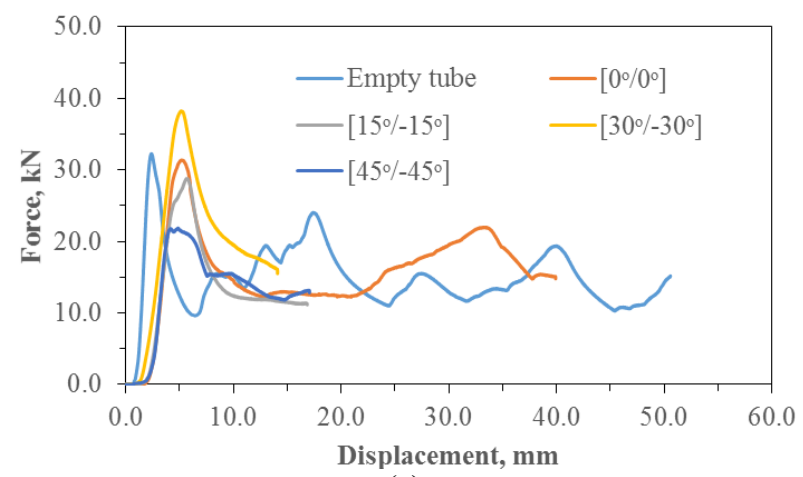

(a)

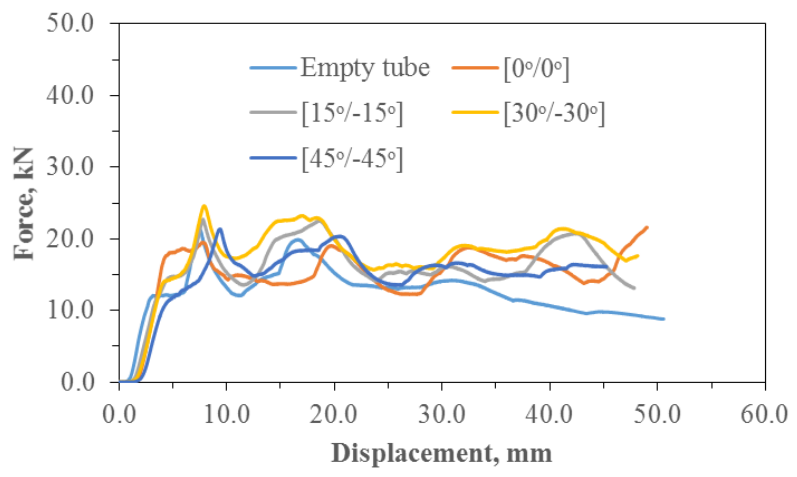

(b)

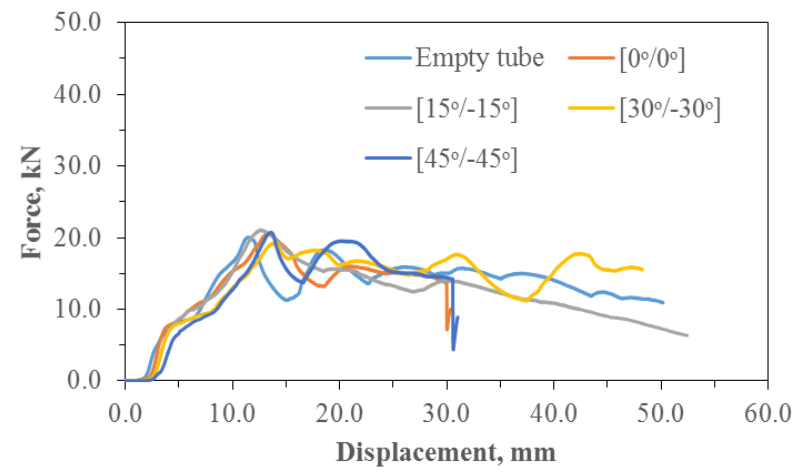

(c)

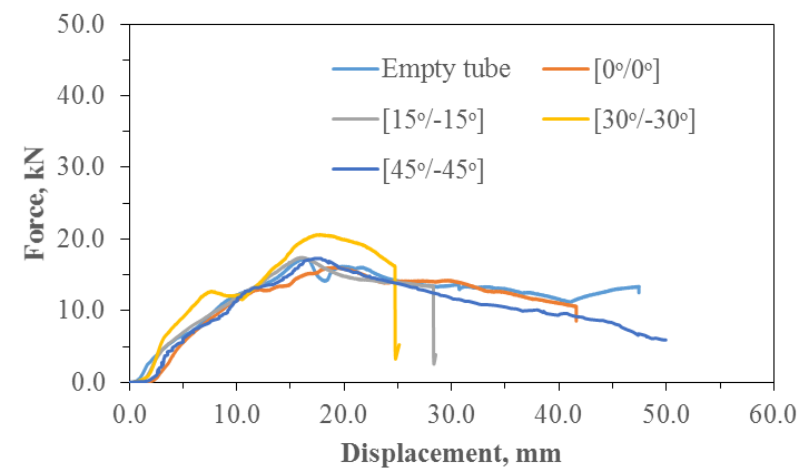

(d)

Figure 3. Effect of oblique compression on the crushing performances when fibre orientations are varied, (a) $0^{\circ}$, (b) $5^{\circ}$, (c) $10^{\circ}$ and (d) $15^{\circ}$.

\section{Results and discussion}

Figure 3 shows the responses of force versus displacement curves of hybrid tubes under normal and oblique compression. Figure 3(a) shows the forcedisplacement curves under axial compression. It is observed that the curves followed a typical diagram 
where in the first stage force is linearly related with displacements until it is reached maximum forces. Once plastic deformation firstly occurred, the maximum forces dropped drastically before it is fluctuated when the tubes experienced progressive collapses. This region is also known as a plateau stage.

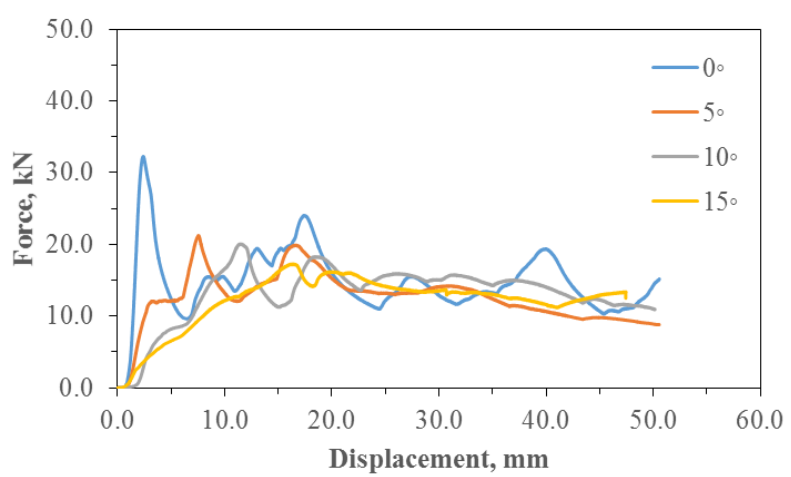

(a)

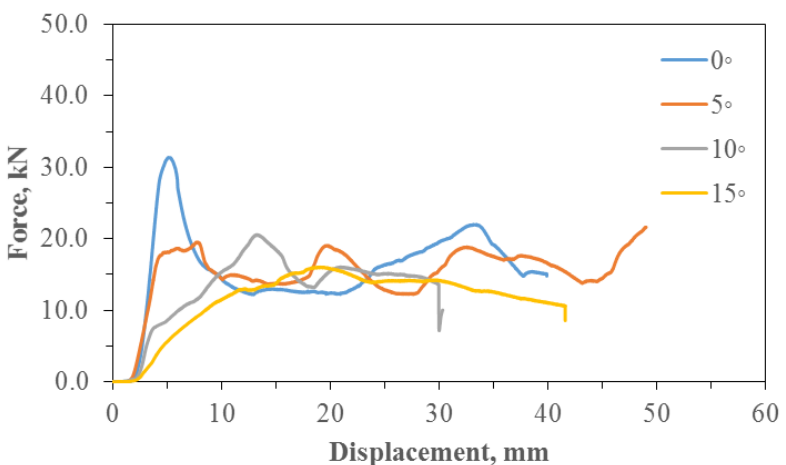

(b)

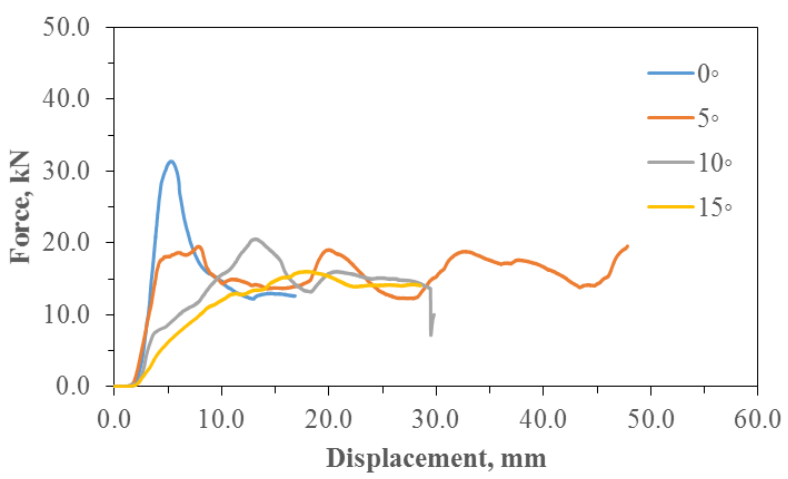

(c)

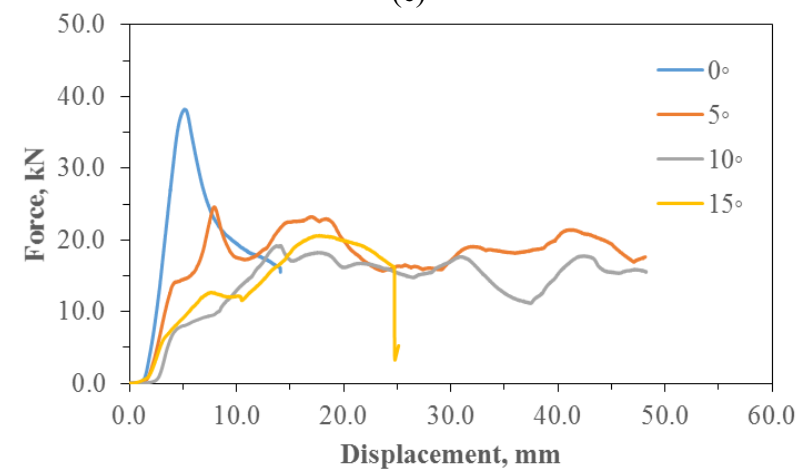

(d)

Figure 4. Effect of fiber orientations on the crushing performances when oblique compression are varies, (a) Empty tube, (b) $\left[15^{\circ} /-15^{\circ}\right]$, (c) $\left[30^{\circ} /-30^{\circ}\right]$ and (d) $\left[45^{\circ} /-45^{\circ}\right]$.
For all cases of oblique compression as in Figures 3(b)-3(d), the present of oblique compression insignificantly contributed to the enhancement of the force-displacement responses. This is due to the fact that the introduction of oblique angles contributed to the creation of stress concentration resulted of bending moments. It is observed that the tubes are not fully experienced progressive collapses due to the eccentricity of compressions.

Figure 4 obviously reveals the roles of oblique angles on the responses of force versus displacement curves. Under axial compression, it is observed that increasing the fibre orientations to $\left[ \pm 45^{\circ}\right]$ capable to increase the peak forces when compared with empty tubes as in Figure 4(a). Once fibre reinforced composites are introduced around the outer surface of tubes, the forcedisplacement curves are observed to slightly increase as compared with empty tubes as in Figure 4(b)-4(d) especially in the first deformation stages. For the second stage, there is not significant deference between the curves indicating that the composites are not played an important role in increasing the mean forces. This is probably the plastic strain of tubes are higher than the composites where the composites do not have enough strength to resist the tube deformations.

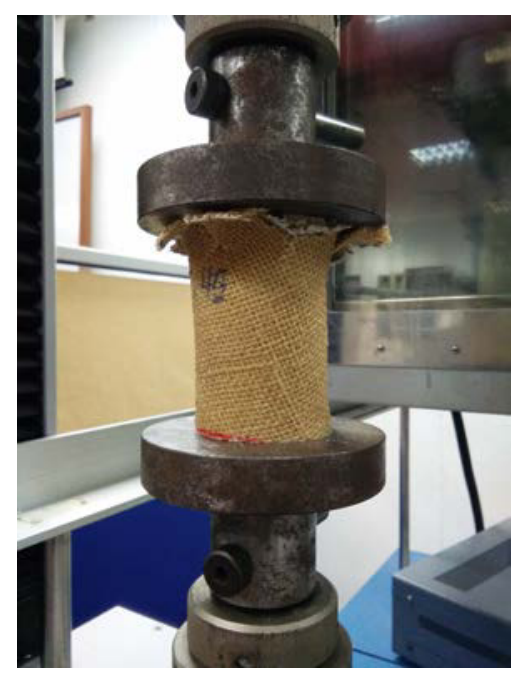

(a)

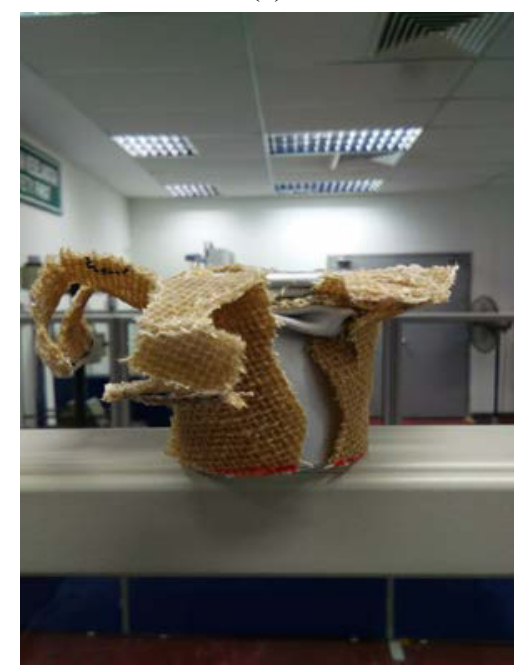

(b) 


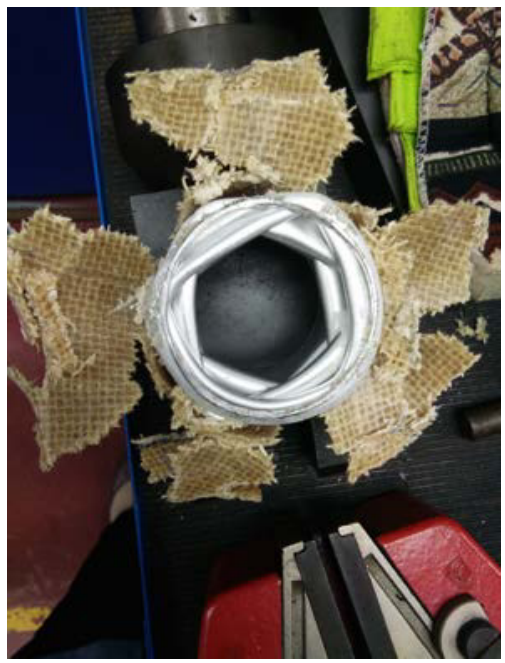

(c)

Figure 5. Crushing mechanisms of $\left[ \pm 45^{\circ}\right]$ fibre orientations wrapped around the aluminium tubes, (a) initial stage deformation, (b) final failure of hybrid tube and (c) area view of (b) under axial compression.

Figure 5 displays the crushing mechanisms of hybrid tubes under axial compression. The tube is wrapped with $45^{\circ}$ fibre orientations. Figure 5(a) shows the deformation captured just after the peak force is achieved. It can be observed that composites experienced large fragmentations. This indicated that the composites unable to absorb crushing energy effectively. This behaviour is similar with the results with Figure 4 where there is not much different between hybridized and empty tubes. Large fragmentations are also observed for the case of final crushed condition as in Figures 5(b) and 5(c). This crushing mechanisms gave a strong evidence that natural fibre can be used to reinforce tubes however it is not absorbed crushing energy efficiently.

\section{Conclusion}

One of important conclusion can be obtained from these experimental works is by wrapping the tubes with woven kenaf fibre reinforced composites capable to enhance the responses of force versus displacement curves where both maximum and mean forces increased mostly for axial compressions. However when oblique compressions are introduced, there is no obvious peak force has occurred fortunately mean force is remain the same as the results obtained from axial compression. Based on the observations of mechanical deformation, there is large composite fragmentations occurred. This indicated that woven kenaf fibre composites are unable to absorb crushing energy efficiently.

\section{References}

1. A. Eyvazian, M.K Habibi, A.M. Hamouda, R, Hedayati. Materials and Design 54, 1028-1038 (2014).

2. A. Eyvazian. MATEC Web of Conferences 40, 02010 (2016)

3. M.Y. Huang, Y.S. Tai, H.T. Hu. Theoretical and Applied Fracture Mechanics 54, 44-53 (2010).

4. D.A. Galib, A. Limam. Thin-Walled Structures 42, 1103-1137 (2004).

5. R. Kalhor, H. Akbarshahi, S.W. Case. Composite Structures 147, 231-246 (2016).

6. H. El-Hage, P.K. Mallick, N. Zamani. Composite Structures 73, 505-514 (2006).

7. K.C. Shin, J.J. Lee, K.H. Kim, M.C. Song, J.S. Huh. Composite Structures 57, 279-287 (2002).

8. M.R. Sanjay, G.R. Arpitha, B. Yogesha. Materials Today 2, 2959-2967 (2015).

9. V. Mittal, R. Saini, S. Sinha. Composite Part B: Engineering 99, 425-435 (2016).

10. T. Gurunathan, S. Mohanty, S.K. Nayak. Composite Part A: Applied Science and Manufacturing 77, 1-25 (2015).

11. N. Saba, M.T. Paridah, M. Jawaid. Construction and Building Materials 76, 87-96 (2015).

12. A.E Ismail. International Journal of Engineering and Technology 6, 2662-2668 (2015).

13. A. E. Ismail. International Journal of Engineering and Technology 7, 1098-1104 (2015).

14. S. N. A. Khalid, A.E Ismail, M.H. Zainulabidin. Applied Mechanics and Materials 773, 134-138 (2015).

15. M. A. Ismail, A.E. Ismail. International Journal of Mechanical and Mechatronics Engineering 15, 100104 (2015).

16. A. E. Ismail. Jurnal Teknologi 78, 45-50 (2016).

17. A. E. Ismail. International Journal of Mechanical and Mechatronics Engineering 16, 49-53 (2016).

18. A. E. Ismail. International Journal of Mechanical and Mechatronics Engineering 16, 65-69 (2016).

19. A. E. Ismail, A. L. Mohd Tobi. ARPN Journal of Engineering and Applied Science 11, 8668-8672 (2016). 